Araştırma Makalesi/Research Article

\title{
Investigating the Technological Pedagogical Content Knowledge of Primary Teachers
}

\author{
Ali Oktay AZGIN1 1 (D), Burcu ŞENLER ${ }^{2 *}$ \\ Muğla Sıtkı Koçman Üniversitesi, Ĕ̆itim Bilimleri Enstitüsü, alioktayazgin@gmail.com \\ ${ }^{2}$ Muğla Sıtkı Koçman Üniversitesi, Eğitim Fakültesi, Temel Eğitim Bölümü, bsenler@mu.edu.tr \\ * Corresponding Author: bsenler@mu.edu.tr
}

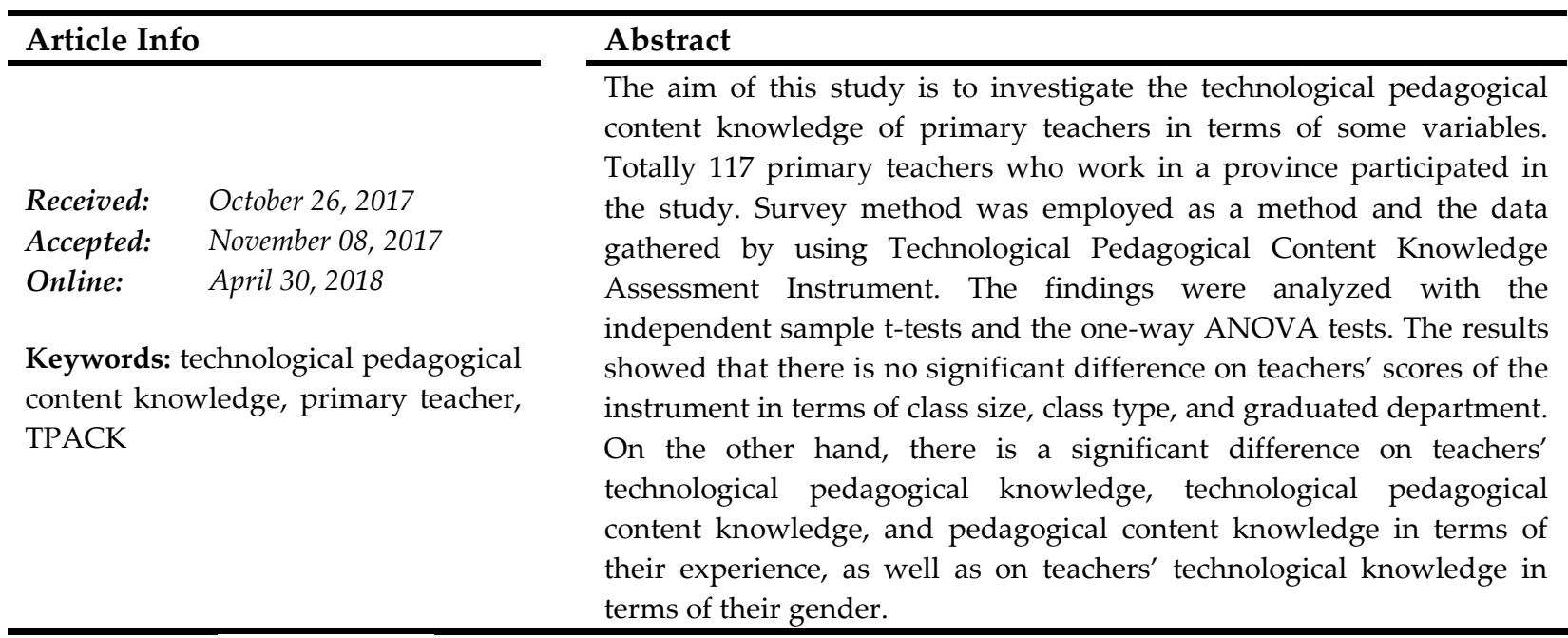

open access Crossmark (C)

To cite this article: Azgın, A. O. \& Şenler, B. (2018). İlkokullarda görev yapan sınıf öğretmenlerinin teknolojik pedagojik alan bilgilerinin incelenmesi. Journal of Computer and Education Research, 6 (11), 47-64. https://doi.org/10.18009/jcer.346858

\section{İlkokullarda Görev Yapan Sınıf Öğretmenlerinin Teknolojik Pedagojik Alan Bilgilerinin İncelenmesi}

\begin{tabular}{|c|c|}
\hline Makale Bilgisi & Öz \\
\hline $\begin{array}{ll}\text { Geliş: } & \text { 26 Ekim } 2017 \\
\text { Kabul: } & \text { 08 Kasım } 2017 \\
\text { Yayın: } & \text { 30 Nisan } 2018 \\
\text { Anahtar } & \text { kelimeler: teknolojik } \\
\text { pedagojik alan bilgisi, sinıf } \\
\text { öğretmeni, TPAB }\end{array}$ & $\begin{array}{l}\text { Bu araştırmanın amacı, ilkokullarda görev yapan sınıf öğretmenlerinin } \\
\text { teknolojik pedagojik alan bilgilerinin bazı değişkenlere göre incelenmesidir. } \\
\text { Araştırmanın çalışma grubunu bir ilçede görev yapan } 117 \text { sınıf öğretmeni } \\
\text { oluşturmaktadır. Araştırmada nicel araştırma yöntemlerinden tarama yöntemi } \\
\text { kullanılmıstır. Veriler, “Öğretmen Adaylarının Teknolojik Pedagojik Alan } \\
\text { Bilgisini Değerlendirme Ölçeği” kullanılarak toplanmıştır. Çalışmada elde edilen } \\
\text { veriler bağımsız t-testleri ve tek yönlü varyans analizi testleri ile analiz } \\
\text { edilmiştir. Analiz sonuçlarına göre öğretmenlerin teknolojik pedagojik alan } \\
\text { bilgisi ölçeğinin tüm alt boyutlarının, öğretmenlerin öğretim yaptıkları sınıfın } \\
\text { mevcudu ve sınıf türü ile mezun oldukları bölümlere göre farklılaşmadığı } \\
\text { görülmüştür. Öte yandan, teknolojik pedagojik bilgi, teknolojik pedagojik alan } \\
\text { bilgisi ve pedagojik alan bilgisi alt boyutlarında öğretmenlerin mesleki kıdem } \\
\text { yıllarına göre; teknoloji bilgisi alt boyutunda cinsiyete göre anlamlı bir farklıllı } \\
\text { saptanmıștır. }\end{array}$ \\
\hline
\end{tabular}




\section{Summary}

\section{Investigating the Technological Pedagogical Content Knowledge of Primary Teachers}

\section{Introduction}

The rapid development of technology requires our teachers to be able to follow and adapt to these changes as hardware. In this context, it is necessary for teachers to develop themselves both technologically and pedagogically and to carry forward these developments. Teachers should be able to combine technological, pedagogical and content knowledge together to create an effective learning-teaching environment by selecting the technological materials appropriate to the content knowledge and the pedagogical method to be used in their lessons (Karakuyu \& Karakuyu, 2016).

Technological Pedagogical Content Knowledge (TPACK) is what teachers know about the subjects covered by the technology they use, which pedagogical techniques they need to use to teach a subject, how to use it to provide better education for the students, and how to use them to build new information by actively moving the forefront (Mishra \& Koehler, 2006; Sailing, Tokmak, Özbelen \& Incikab1, 2013). TPACK is the most comprehensive and meaningful part of the content of each segment, together with the integration of Technological Knowledge, Pedagogical Knowledge and Content Knowledge (Koehler \& Mishra, 2005).

When the studies in the literature about TPACK are examined, it is seen that the studies were mostly done on mathematics and science teachers and pre-service teachers. A relatively limited number of studies have been conducted for primary teachers and primary pre-service teachers. It is believed that the study of TPACK on the basis of variables such as gender, seniority year, type of classroom, and classroom availability of the classroom teachers will contribute to the literature due to the limited number of classroom teachers' studies. Therefore, the aim of this study is to investigate the technological pedagogical content knowledge of primary teachers in terms of some variables. The research questions are as follow:

1. Does primary teachers' technological pedagogical content knowledge differ in terms of their department they graduated? 
2. Does primary teachers' technological pedagogical content knowledge differ in terms of their gender?

3. Does primary teachers' technological pedagogical content knowledge differ in terms of their experience?

4. Does primary teachers' technological pedagogical content knowledge differ in terms of the class type they do teaching?

5. Does primary teachers' technological pedagogical content knowledge differ in terms of the class size they do teaching?

\section{Methodology}

Survey method was employed as a method of the study. Totally 117 primary teachers (71 female, 46 male, the mean of age 42.7) who works in schools participated in the study. The data gathered by using Technological Pedagogical Content Knowledge Assessment Instrument which was developed by Schmidt et al. (2010), and adapted by Haciömeroğlu, Şahin and Arcagök (2014). The instrument included 10 dimensions, namely technological knowledge, content knowledge (mathematics, social, science, and literacy), Pedagogical Knowledge, Pedagogical Content Knowledge, Technology Related Teaching Knowledge, Technology Related Pedagogical Content Knowledge, and Technological Pedagogical Content Knowledge. This 5-likert type instrument consists of 46 items.

\section{Findings}

The findings were analyzed with the independent sample t-tests and the one-way ANOVA tests. The results showed that there is no significant difference on teachers' scores of the instrument in terms of class size, class type, and graduated department. On the other hand, there is a significant difference on teachers' technological pedagogical knowledge, technological pedagogical content knowledge, and pedagogical content knowledge in terms of their experience, as well as on teachers' technological knowledge in terms of their gender.

\section{Discussion and Conclusion}

Primary teachers' the technological pedagogical content knowledge was investigated in terms of some variables. According to the results there is a significant difference on teachers' technological pedagogical knowledge, technological pedagogical content knowledge, and pedagogical content knowledge in terms of their experience. The teachers who have 30-39 years experience had higher score than the teachers who have 10-19 years experience in pedagogical content knowledge dimension. The study of Karadeniz and Vatanartiran (2015) supports this result. Teachers' experience influences their selection of teaching strategies, methods and techniques, and assessment as well as being effective that 
this may explain this result. The teachers who have 20-29 years' experience had higher score than the teachers who have 10-19 years' experience in technology related pedagogical content knowledge dimension and technological pedagogical content knowledge dimension. Since young people follow new technological developments more, get familiar them easier, and use these developments more, teachers with 10-19 years experiences were expected to get higher score. However, similar to pedagogical content knowledge, the more experience teachers have, the higher score they had in technology related pedagogical content knowledge dimension and technological pedagogical content knowledge dimension. In future studies, the reason of these results may be investigated. 


\section{Giriş}

Teknolojinin hızlı bir şekilde gelişimi sonucu hayatımızın her noktasına dokunması, eğitim anlayışımızın değişimi sonucu gerçekleşen köklü değişiklikler, öğretmenlerimizin donanım olarak bu değişimleri takip edebilmelerini ve uyum sağlayabilmelerini gerektirmektedir. Bu bağlamda, öğretmenlerin hem teknolojik hem de pedagojik açıdan kendilerini geliştirmeleri ve bu gelişimlerini sürdürerek ileriye taşımaları gerekmektedir. Çünkü etkili bir şekilde teknolojiyi kullanabilmek için değişimleri takip etmek ve değişimlere adapte olmak önemlidir. Öğretmenlerin teknoloji kullanmayı ve bunları derslerine nasıl aktaracağını bilmesi de önemli olmaktadır. Öğretmenlerin derslerinde alan bilgilerine ve kullanacakları pedagojik yönteme uygun teknolojik materyalleri seçerek etkili bir öğrenme-öğretme ortamı oluşturması yani teknolojik, pedagojik ve alan bilgilerini birlikte harmanlayabilmeleri gerekir (Karakuyu \& Karakuyu, 2016).

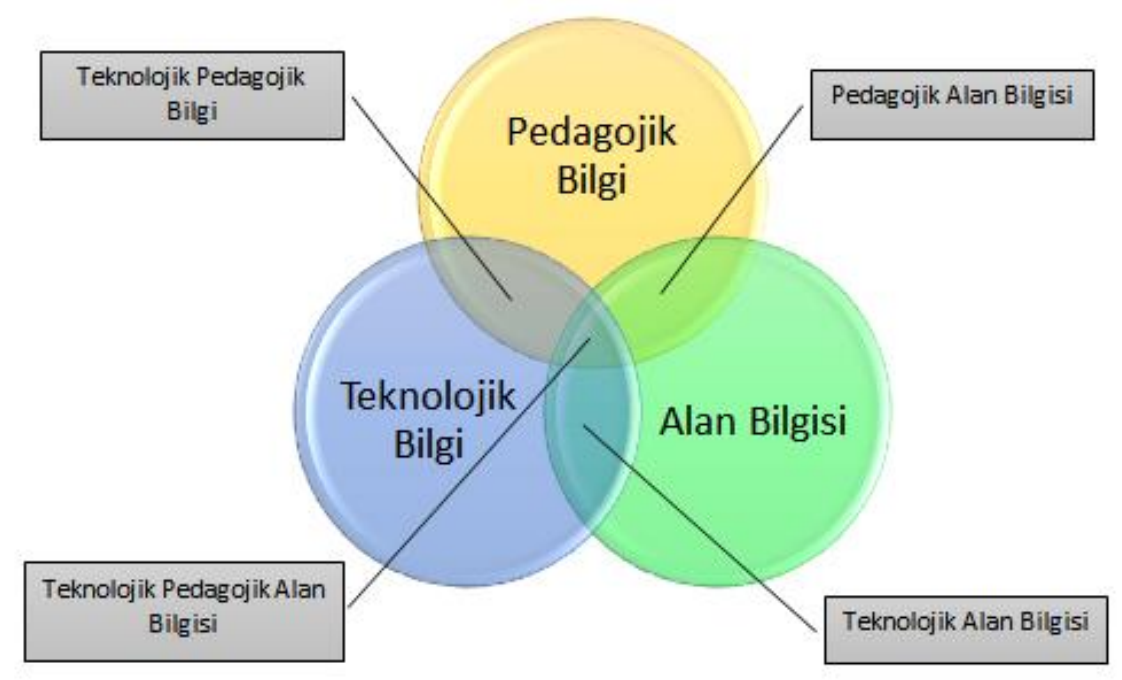

Şekil 1. Teknolojik pedagojik alan bilgisinin öğeleri (Mishra \& Koehler, 2006)

Teknolojik Pedagojik Alan Bilgisi (TPAB), öğretmenlerin kullanacağı teknolojinin hangi konuları içerdiğini, bir konuyu öğretmek için hangi pedagojik teknikleri uygulaması gerektiğini, öğrencilere daha iyi bir eğitim sağlamak ve önbilgilerini harekete geçirerek yeni bilgiler inşa etmek için nasıl kullanacağını bilmesidir (Mishra \& Koehler, 2006; akt. Yelken, Tokmak, Özgelen \& İncikabı, 2013). Teknolojik Pedagojik Alan Bilgisi (TPAB), Teknolojik Bilgi (TB), Pedagojik Bilgi (PB) ve Alan Bilgisinin (AB) birleşimi olmakla birlikte, TPAB her 
bir parçanın içeriğinin en kapsamlı ve anlamlı bir bütünü olmaktadır (Koehler \& Mishra, 2005).

TPAB, Şekil 1'de görüldüğü gibi 7 bilgi alanından oluşmaktadır. Bunlar; Teknoloji Bilgisi (TB), Pedagoji Bilgisi (PB), Alan Bilgisi (AB), Pedagojik Alan Bilgisi (PAB), Teknolojik Alan Bilgisi (TAB), Teknolojik Pedagoji Bilgisi (TPB) ve Teknolojik Pedagojik Alan Bilgisi (TPAB)'dir (Karakuyu \& Karakuyu, 2016). Bu bilgi alanları şu şekilde tanımlanmaktadır:

Teknolojik Bilgi (TB): Sürekli değişen ve gelişen teknolojiyi bilme ve kullanma hakkındaki bilgidir.

Alan Bilgisi (AB): Öğretilecek olan konularla ilgili bilgidir. $A B$, her alandaki konuları ve bu konuların dayandığı ilke, teori ve kuralları içerir (Koehler \& Mishra, 2009).

Pedagojik Bilgi (PB): PB, süreç ve uygulamalar ya da öğretim yöntemleri ve öğrenme ile eğitim amaçları ve hedeflerin nasıl bütünleştirileceği konusundaki bilgidir. PB, öğrencilerin nasıl öğrendiklerini anlama, genel sınıf yönetimi becerileri, dersi planlama, öğretim yöntem ve teknikleri ile hedef kitlenin niteliğini ve öğrencilerin anlamasını değerlendirmek için kullanılan stratejiler hakkında bilgi sahibi olmayı içerir (Canbazoğlu Bilici \& Baran, 2015).

Teknolojik Alan Bilgisi (TAB): Teknolojinin alanla bütünleştirilmesi konusundaki bilgidir (Mishra \& Koehler, 2006).

Pedagojik Alan Bilgisi (PAB): Özelde bir konunun etkili ve verimli bir şekilde öğrenilmesini veya öğretilmesini içiren bilgidir.

Teknolojik Pedagojik Alan Bilgisi (TPAB): TPAB, üç çekirdek bilgi bileşeninin ötesinde konu alan bilgisi, pedagojik bilgi ve teknolojik bilgi arasındaki etkileşimlerden ortaya çıan bir bilgi türüdür (Canbazoğlu Bilici \& Baran, 2015). Öğretmenin konu öğretiminde, konu alanına hâkimiyeti ile birlikte ilgili konunun aktarılmasında gerekli teknolojileri ve pedagojik stratejileri seçme ve kullanabilme bilgisidir (Jang \& Chan, 2010).

Teknolojik Pedagojik Alan Bilgisi ile ilgili literatürdeki çalışmalara bakıldığında çalışmaların daha çok matematik ve fen bilgisi öğretmenleri ile öğretmen adayları üzerine yapıldığı görülmüştür. Sınıf öğretmenlerine ve sınıf öğretmeni adaylarına yönelik nispeten sınırlı sayıda çalışma yapılmıştır. Karakuyu ve Karakuyu (2016) çalışmasında sınıf öğretmenleri adaylarının öz-yeterlikleri ile TPAB’leri arasında anlamlı bir ilişkinin olmadığı sonucuna ulaşmıştır. Karadeniz ve Vatanartıran (2015)'in çalışmasında sınıf öğretmenlerinin TPAB çerçevesinde kendilerini yeterli buldukları, cinsiyete göre erkek öğretmenlerin 
teknoloji bilgisi algılarının kadın öğretmenlere göre daha yüksek olduğu, 16 yıl ve üzeri kıdem yılına sahip öğretmenlerin alan bilgisi ve pedagojik alan bilgisi alt boyutlarında 1-5 yıl arası kıdem yılına sahip öğretmenlere göre kendilerini daha yeterli buldukları tespit edilmiştir. Hırça ve Şimşek (2013)'in sınıf öğretmen adayları üzerine yaptıkları çalışmada sınıf öğretmeni adaylarının teknolojinin öğretim sürecindeki rolüne inandıklarını ama teknoloji kullanma becerilerinin yetersiz olduğu, öğretim sürecinde teknoloji ile pedagojiyi birleştirme konusunda zorluk yaşadıkları sonuçlarına ulaşmışlardır. Şad, Açıkgül ve Delican (2015)'in farklı branşlardan son sınıf öğretmen adayları üzerine yaptıkları çalışmada genel olarak öğretmen adaylarının TPAB konusunda kendilerini yeterli gördükleri, sınıf öğretmeni adaylarının pedagojik bilgi alt boyutunda kendilerini iyi düzeyde bulduklarını ifade etmişlerdir. Yavuz-Konakman, Yanpar-Yelken ve Sancar-Tokmak (2012)'nin sınıf öğretmeni adayları üzerine yaptıkları çalışmada ise sınıf öğretmeni adaylarının TPAB alt boyutlarında orta seviyenin üzerinde bir öz-yeterliğe sahip oldukları tespit edilmiştir.

TPAB üzerine sınıf öğretmenlerinin mezun oldukları alan, cinsiyet, kıdem yılı, öğretim yapılan sınıf türü, öğretim yapılan sınıfın mevcudu gibi değişkenlere göre incelenmesinin, sınıf öğretmenlerine yönelik çalışmaların sınırlı sayıda olması nedeniyle literatüre katkı sağlayacağı düşünülmektedir. Bu bağlamda, bu araştırmanın amacı, ilkokullarda görev yapan sınıf öğretmenlerinin teknolojik pedagojik alan bilgilerinin bazı değişkenlere göre incelenmesidir. Çalışma ile ilgili araştırma soruları aşağıda yer almaktadır: Sınıf öğretmenlerinin teknolojik pedagojik alan bilgileri;

1) Mezun oldukları alana göre farklılaşmakta mıdır?

2) Cinsiyetlerine göre farklılaşmakta mıdır?

3) Kıdem yıllarına göre farklılaşmakta mıdır?

4) Öğretim yaptıkları sınıfın türüne göre farklılaşmakta mıdır?

5) Öğretim yaptıkları sınıfın mevcuduna göre farklılaşmakta mıdır?

\section{Yöntem}

\section{Çalışmanın Modeli}

$\mathrm{Bu}$ araştırma, nicel araştırma yöntemlerinden tarama (survey) modeli kullanılarak gerçekleştirilmiştir. Tarama modeli, bir grubun belirli özelliklerini belirlemek için verilerin toplanmasını amaçlayan çalışmalar için kullanılmaktadır (Büyüköztürk, Kılıç Çakmak, Akgün, Karadeniz \& Demirel, 2014, s.14). 
Çalışma Grubu

$\mathrm{Bu}$ araştırmanın örneklemini, Ege Bölgesi'nde bir ilçede görev yapan uygun örnekleme yöntemi ile ulaşılan 117 sınıf öğretmeni (71 kadın ve 46 erkek; yaş ortalaması 42,7) oluşturmaktadır. Uygun örnekleme yöntemi, zaman, para ve işgücü açısından örneklemin kolay ulaşılabilir ve uygulama yapılabilir birimlerden seçilmesi ile yapılır (Büyüköztürk, 2012). Çalışmaya katılan sınıf öğretmenlerinin mezun oldukları bölümler Tablo 1'de belirtilmiştir.

Tablo 1. Sınıf Öğretmenlerinin Mezun Oldukları Bölümlere Göre Dağılımı

\begin{tabular}{lcc}
\hline & Bölümler & Frekans \\
\hline Sinıf Öğretmenliği & 91 \\
Branş Öğretmenliği & 15 \\
Diğer Fakülteler & 11 \\
\hline TOPLAM & 117 \\
\hline
\end{tabular}

Çalışmaya katılan sınıf öğretmenlerinden 107 sınıf öğretmeni tek şube olarak, 10 sınıf öğretmeni ise birleştirilmiş iki şube olarak eğitim-öğretim sürecini devam ettirmektedir, öğretmenlerin sahip oldukları kıdem yılları Tablo 2'de belirtilmiştir.

Tablo 2. Sınıf Öğretmenlerinin Sahip Oldukları Kıdem Yıllarına Göre Dağılımı

\begin{tabular}{cc}
\hline Kidem Y1lı Aralığ 1 & Frekans \\
\hline $0-9$ & 18 \\
$10-19$ & 41 \\
$20-29$ & 38 \\
$30-39$ & 20 \\
\hline TOPLAM & 117 \\
\hline
\end{tabular}

Çalışmaya katılan sınıf öğretmenlerinin sahip oldukları sınıf mevcutları Tablo 3'de belirtilmiştir.

Tablo 3. Sınıf Öğretmenlerinin Sahip Olduğu Sınıf Mevcuduna Göre Dağılımı

\begin{tabular}{cc}
\hline Sinif Mevcudu Aralığ & Frekans \\
\hline $0-9$ & 10 \\
$10-19$ & 45 \\
$20-29$ & 38 \\
$30-39$ & 20 \\
\hline TOPLAM & 113 \\
\hline
\end{tabular}

\section{Veri Toplama Aracı}

Veriler Schmidt vd. (2010) tarafından geliştirilen ve Hacıömeroğlu, Şahin ve Arcagök (2014) tarafından Türkçe'ye uyarlanan Öğretmen Adaylarının Teknolojik Pedagojik Alan Bilgisini Değerlendirme Ölçeği kullanılarak toplanmıştır. Ölçek Teknoloji Bilgisi (TB), Alan Bilgisi ( $\mathrm{AB}$ matematik, $\mathrm{AB}$ sosyal bilimler, $\mathrm{AB}$ fen, $\mathrm{AB}$ okuma yazma), Pedagojik Bilgi (PB), 
Pedagojik Alan Bilgisi (PAB), Teknolojik Alan Bilgisi (TAB), Teknolojik Pedagojik Bilgi (TPB), Teknolojik Pedagojik Alan Bilgisi (TPAB) olmak üzere 10 boyuttan ve 46 maddeden oluşmaktadır. Ölçek 5'li likert tipindedir (5=tamamen katılıyorum, 4=katılıyorum, 3=kararsızım, 2=katılmıyorum, 1=kesinlikle katılmıyorum). Tablo 4'te Türkçe'ye uyarlama çalışmasının ve bu çalışmanın Cronbach's Alfa güvenirlik katsayı değerleri sunulmaktadır.

Tablo 4. Teknolojik Pedagojik Alan Bilgisi Değerlendirme Ölçeği Güvenirlik Katsayıları

\begin{tabular}{lccc}
\hline Boyutlar & Madde Sayısı & $\begin{array}{c}\text { Uyarlama Çalışmasındaki } \\
\alpha\end{array}$ & $\begin{array}{c}\text { Bu çalışmadaki } \\
\alpha\end{array}$ \\
\hline TB & 7 & 0.87 & 0.88 \\
ABM & 3 & 0.84 & 0.90 \\
ABS & 3 & 0.87 & 0.93 \\
ABF & 3 & 0.77 & 0.95 \\
ABO & 3 & 0.86 & 0.95 \\
PB & 7 & 0.89 & 0.95 \\
PAB & 4 & 0.81 & 0.91 \\
TAB & 4 & Belirtilmemiş & 0.88 \\
TPB & 4 & 0.87 & 0.89 \\
TPAB & 8 & 0.82 & 0.94 \\
\hline Ölçeğin Tamamı & 47 & 0.94 & 0.97 \\
\hline
\end{tabular}

\section{Verilerin Analizi}

Sınıf öğretmenlerine uygulanan Teknolojik Pedagojik Alan Bilgisi Değerlendirme Ölçeği ile toplanan verilerin analizinde PASW 21 paket programı kullanılmıştır. Verilerin normal dağılım gösterip göstermediği ve kullanılan test türüne göre ilgili varsayımlar test edilmiştir. Sınıf öğretmenlerinin teknolojik pedagojik alan bilgilerini, cinsiyet değişkeni ve sınıf türü değişkeni açısından incelemek için bağımsız $t$ testleri; kıdem yılı değişkeni (1-9 kıdem yılı, 10-19 kıdem yılı, 20-29 kıdem yılı, 30-39 kıdem yılı şeklinde gruplandırılarak), sınıf mevcudu değişkeni (10'dan düşük sınıf mevcudu, 10-19 sınıf mevcudu, 20-29 sınıf mevcudu, 30 ve 30'dan yüksek sınıf mevcudu şeklinde gruplandırılarak) ve mezun oldukları alan değişkeni (sınıf öğretmenliği anabilim dalı, branş öğretmenliklerinin anabilim dalları ve diğer fakültelerden mezun şeklinde gruplandırılarak) açısından incelemek için ise tek yönlü varyans analizi (One-way ANOVA) testleri kullanılmıştır. Varyans analizleri sonucunda gruplar arasında anlamlı farklılık olması durumunda, farklılı̆̆ın hangi gruplardan kaynaklandığı Scheffe testi kullanılarak belirlenmiştir.

\section{Bulgular}

Çalışmanın birinci alt probleminde, sınıf öğretmenlerinin teknolojik pedagojik alan bilgisi değerlendirme ölçeği alt boyutlarının mezun oldukları alana göre farklılaşıp 
farklılaşmadığı tek yönlü varyans analizi (One-way ANOVA) ile incelenmiştir. Yapılan test sonucu Tablo 5'te verilmiştir.

Tablo 5. Sınıf Öğretmenlerinin Teknolojik Pedagojik Alan Bilgisi Değerlendirme Ölçeği Alt Boyutlarının Mezun Oldukları Alana İlişkin Durumları

\begin{tabular}{|c|c|c|c|c|c|c|}
\hline $\begin{array}{l}\text { Alt } \\
\text { Boyutlar }\end{array}$ & $\begin{array}{l}\text { Varyansin } \\
\text { Kaynağ1 }\end{array}$ & $\begin{array}{l}\text { Kareler } \\
\text { Toplamı }\end{array}$ & Sd & $\begin{array}{l}\text { Kareler } \\
\text { Toplamı }\end{array}$ & $\mathrm{F}$ & $\mathrm{p}$ \\
\hline \multirow[t]{3}{*}{$\mathrm{TB}$} & Gruplar arası & 33,68 & 2 & 16,84 & 0,72 & 0,49 \\
\hline & Grup içi & 2663,25 & 114 & 23,36 & & \\
\hline & Grup içi & 2663,25 & 114 & 23,36 & 0,40 & 0,67 \\
\hline \multirow[t]{2}{*}{$\mathrm{ABM}$} & Gruplar arası & 2,33 & 2 & 1,17 & & \\
\hline & Grup içi & 328,90 & 114 & 2,89 & & \\
\hline \multirow{2}{*}{ ABS } & Gruplar arası & 3,50 & 2 & 1,75 & 0,46 & 0,64 \\
\hline & Grup içi & 437,42 & 114 & 3,84 & & \\
\hline \multirow[t]{2}{*}{$\mathrm{ABF}$} & Gruplar arası & 3,37 & 2 & 1,69 & 0,48 & 0,62 \\
\hline & Grup içi & 400,94 & 114 & 3,52 & & \\
\hline \multirow[t]{2}{*}{$\mathrm{ABO}$} & Gruplar arası & 0,13 & 2 & 0,07 & 0,3 & 0,97 \\
\hline & Grup içi & 294,17 & 114 & 2,58 & & \\
\hline \multirow[t]{2}{*}{ PB } & Gruplar arası & 2,15 & 2 & 1,08 & 0,09 & 0,91 \\
\hline & Grup içi & 1337,85 & 114 & 11,74 & & \\
\hline \multirow{2}{*}{$\mathrm{PAB}$} & Gruplar arası & 3,74 & 2 & 1,87 & 0,42 & 0,66 \\
\hline & Grup içi & 503,96 & 114 & 4,42 & & \\
\hline \multirow[t]{2}{*}{ TAB } & Gruplar arası & 7,57 & 2 & 3,79 & 0,85 & 0,43 \\
\hline & Grup içi & 509,66 & 114 & 4,47 & & \\
\hline \multirow[t]{2}{*}{ TPB } & Gruplar arası & 6,80 & 2 & 340 & 0,51 & 0,60 \\
\hline & Grup içi & 766,28 & 114 & 6,72 & & \\
\hline \multirow[t]{2}{*}{ ТРАВ } & Gruplar arası & 7,13 & 2 & 3,56 & 0,18 & 0,84 \\
\hline & Grup içi & 2276,57 & 114 & 19,97 & & \\
\hline
\end{tabular}

Tablo 5'de görüldüğü gibi sınıf öğretmenliği anabilim dalından mezun olan sınıf öğretmenlerinin, branş öğretmenliklerinden mezun sınıf öğretmenlerinin ve diğer alanlardan mezun olan sınıf öğretmenlerinin teknolojik pedagojik alan bilgisi değerlendirme ölçeği alt boyut puanları arasında anlamlı bir fark tespit edilmemiştir $(p>0,05)$.

Çalışmanın ikinci alt probleminde, sınıf öğretmenlerinin teknolojik pedagojik alan bilgisi değerlendirme ölçeği alt boyutlarının cinsiyetlerine göre farklılaşıp farklılaşmadığ bağımsız $\mathrm{t}$ testi ile incelenmiştir. Bağımsız t-test sonuçları Tablo 6'da verilmiştir. 
Tablo 6. Sınıf Öğretmenlerinin Teknolojik Pedagojik Alan Bilgisi Değerlendirme Ölçeği Alt Boyutlarının Cinsiyete İlişkin Durumları

\begin{tabular}{llllllc}
\hline Alt Boyutlar & Gruplar & $\mathrm{N}$ & $\overline{\mathbf{X}}$ & $\mathrm{SS}$ & $\mathrm{t}$ & $\mathrm{p}$ \\
\hline TB & Kadın & 71 & 26,25 & 4,39 & $-3,04$ & 0,00 \\
& Erkek & 46 & 28,93 & 5,05 & & \\
ABM & Kadın & 71 & 13,31 & 1,45 & 1,04 & 0,30 \\
& Erkek & 46 & 12,98 & 2,01 & & \\
ABS & Kadın & 71 & 12,39 & 1,95 & $-1,71$ & 0,09 \\
& Erkek & 46 & 13,02 & 1,90 & & \\
ABF & Kadın & 71 & 12,76 & 1,65 & 0,12 & 0,90 \\
& Erkek & 46 & 12,72 & 2,18 & & \\
ABO & Kadın & 71 & 13,93 & 1,51 & 0,06 & 0,96 \\
& Erkek & 46 & 13,91 & 1,74 & & \\
PB & Kadın & 71 & 32,13 & 3,03 & 0,50 & 0,62 \\
& Erkek & 46 & 31,80 & 3,92 & & \\
PAB & Kadın & 71 & 17,20 & 1,76 & $-0,54$ & 0,59 \\
& Erkek & 46 & 17,41 & 2,53 & & \\
TAB & Kadın & 71 & 17,46 & 2,10 & $-0,30$ & 0,76 \\
& Erkek & 46 & 17,59 & 2,16 & & \\
TPB & Kadın & 71 & 16,80 & 2,52 & $-0,36$ & 0,72 \\
& Erkek & 46 & 16,98 & 2,70 & & \\
TPAB & Kadın & 71 & 34,35 & 4,31 & $-0,10$ & 0,92 \\
& Erkek & 46 & 34,43 & 4,67 & & \\
\hline
\end{tabular}

Tablo 6'te görüldügü üzere kadın ve erkek sınıf öğretmenlerinin teknoloji bilgisi alt boyutu dışındaki teknolojik pedagojik alan bilgisi değerlendirme ölçeği alt boyut puanları arasında anlamlı bir fark görülmemiştir $(\mathrm{p}>0,05)$. Öte yandan, teknoloji bilgisi alt boyutunda kadın sınıf öğretmenlerinin test puan ortalaması ile $(\bar{X}=26,26)$, erkek sınıf öğretmenlerinin test puan ortalaması $(\overline{\mathrm{X}}=28,93)$ arasında erkek sınıf öğretmenleri lehine anlamlı bir fark saptanmıştır $[t(115)=-3,04, p \leq 0,05]$. Erkek sınıf öğretmenlerinin teknoloji bilgileri kadın sınıf öğretmenlerinden anlamlı düzeyde yüksektir.

Çalışmanın üçüncü alt probleminde, sınıf teknolojik pedagojik alan bilgisi değerlendirme ölçeği alt boyutlarının kıdem yıllarına göre farklılaşıp farklılaşmadığ1 tek yönlü varyans analizi (One-way ANOVA) ile incelenmiştir. Analiz sonuçları Tablo 7'de verilmiştir. 
Tablo 7. Sınıf Öğretmenlerinin Teknolojik Pedagojik Alan Bilgisi Değerlendirme Ölçeği Alt Boyutlarının Kıdem Yıllarına İlişkin Durumları

\begin{tabular}{|c|c|c|c|c|c|c|c|}
\hline Alt Boyut & $\begin{array}{l}\text { Varyansın } \\
\text { Kaynağ1 }\end{array}$ & $\begin{array}{l}\text { Kareler } \\
\text { Toplamı }\end{array}$ & Sd & $\begin{array}{l}\text { Kareler } \\
\text { Toplamı }\end{array}$ & $\mathrm{F}$ & $\mathrm{p}$ & $\eta^{2}$ \\
\hline \multirow[t]{2}{*}{ TB } & Gruplar arası & 86,18 & 3 & 28,73 & 1,24 & 0,30 & 0,03 \\
\hline & Grup içi & 2610,74 & 113 & 23,10 & & & \\
\hline \multirow[t]{2}{*}{$\mathrm{ABM}$} & Gruplar arası & 7,92 & 3 & 2,64 & 0,92 & 0,43 & 0,02 \\
\hline & Grup içi & 323,31 & 113 & 2,86 & & & \\
\hline \multirow[t]{2}{*}{ ABS } & Gruplar arası & 18,00 & 3 & 6,00 & 1,60 & 0,19 & 0,04 \\
\hline & Grup içi & 422,92 & 113 & 3,74 & & & \\
\hline \multirow[t]{2}{*}{$\mathrm{ABF}$} & Gruplar arası & 18,89 & 3 & 6,30 & 1,87 & 0,14 & 0,05 \\
\hline & Grup içi & 385,41 & 113 & 3,41 & & & \\
\hline \multirow[t]{2}{*}{$\mathrm{ABO}$} & Gruplar arası & 4,41 & 3 & 1,47 & 0,57 & 0,63 & 0,02 \\
\hline & Grup içi & 289,90 & 113 & 2,57 & & & \\
\hline \multirow[t]{2}{*}{ PB } & Gruplar arası & 48,95 & 3 & 16,32 & 1,43 & 0,24 & 0,04 \\
\hline & Grup içi & 1291,06 & 113 & 11,43 & & & \\
\hline \multirow[t]{2}{*}{ PAB } & Gruplar arası & 35,26 & 3 & 11,75 & 2,81 & 0,04 & 0,07 \\
\hline & Grup içi & 472,43 & 113 & 4,18 & & & \\
\hline \multirow[t]{2}{*}{$\mathrm{TAB}$} & Gruplar arası & 20,25 & 3 & 6,75 & 1,54 & 0,21 & 0,04 \\
\hline & Grup içi & 496,98 & 113 & 4,40 & & & \\
\hline \multirow[t]{2}{*}{ ТPB } & Gruplar arası & 53,48 & 3 & 17,83 & 2,80 & 0,04 & 0,07 \\
\hline & Grup içi & 719,59 & 113 & 6,37 & & & \\
\hline \multirow[t]{2}{*}{ TPAB } & Gruplar arası & 162,54 & 3 & 54,18 & 2,89 & 0,04 & 0,07 \\
\hline & Grup içi & 2121,15 & 113 & 18,78 & & & \\
\hline
\end{tabular}

Pedagojik Alan Bilgisi alt boyutunda 1-9 kıdem yılına sahip sınıf öğretmenlerinin puanları $(\overline{\mathrm{X}}=17,28), 10-19$ kıdem yılına sahip sınıf öğretmenlerinin puanları $(\overline{\mathrm{X}}=16,61), 20-29$ kıdem yılına sahip sınıf öğretmenlerinin ortalaması $(\bar{X}=17,58)$ ve 30-39 kıdem yılına sahip sınıf öğretmenlerinin puanları $(\overline{\mathrm{X}}=18,10)$ arasında istatistiksel olarak anlamlı bir fark tespit edilmiştir $[F(3,113)=2,81, \mathrm{p} \leq 0,05]$. Yapılan Scheffe çoklu karşılaştırma testi sonucunda, anlamlı farkın, 10-19 kıdem yılına sahip sınıf öğretmenleri ile 30-39 kıdem yılına sahip sınıf öğretmenleri arasında 30-39 kıdem yılına sahip sınıf öğretmenleri lehine olduğu görülmüştür. Buna göre, 30-39 kıdem yılına sahip sınıf öğretmenlerinin pedagojik alan bilgileri 10-19 kıdem yılına sahip sınıf öğretmenlerinin pedagojik alan bilgilerinden anlamlı düzeyde daha yüksektir. Analiz sonucunda hesaplanan etki büyüklüğü $\left(\eta^{2}=0,07\right)$ bu farkın Cohen (1988) parametrelerine göre orta düzeyde etki büyüklüğüne sahip olduğunu göstermektedir.

Teknolojik Pedagojik Bilgi alt boyutunda 1-9 kıdem yılına sahip sınıf öğretmenlerinin puanları $(\bar{X}=17,06), 10-19$ kıdem yılına sahip sınıf öğretmenlerinin puanları $(\bar{X}=15,98), 20-29$ kıdem yılına sahip sınıf öğretmenlerinin puanları $(\bar{X}=17,53)$ ve 30-39 kıdem yılına sahip sinıf öğretmenlerinin puanları $(\overline{\mathrm{X}}=17,30)$ arasında istatistiksel olarak anlamlı bir fark tespit 
edilmiştir $[F(3,113)=2,80, \mathrm{p} \leq 0,05]$. Yapılan Scheffe çoklu karşılaştırma testi sonucunda, anlamlı farkın, 10-19 kıdem yılına sahip sınıf öğretmenleri ile 20-29 kıdem yılına sahip sınıf öğretmenleri arasında 20-29 kıdem yılına sahip sınıf öğretmenleri lehine olduğu görülmüştür. Buna göre, 20-29 kıdem yılına sahip sınıf öğretmenlerinin teknolojik pedagojik bilgilerinin 10-19 kıdem yılına sahip sınıf öğretmenlerinin teknolojik pedagojik bilgilerinden anlamlı derecede daha yüksektir. Analiz sonucunda hesaplanan etki büyüklüğü $(\eta 2=0,07)$ bu farkın Cohen (1988) parametrelerine göre orta düzeyde etki büyüklügüne sahip olduğunu göstermektedir.

Teknolojik Pedagojik Alan Bilgisi alt boyutunda 1-9 kıdem yılına sahip sinıf öğretmenlerinin ortalaması $(\overline{\mathrm{X}}=34,11), 10-19$ kıdem yılına sahip sınıf öğretmenlerinin puanları ( $\overline{\mathrm{X}}=32,93), 20-29$ kıdem yılına sahip sınıf öğretmenlerinin puanları $(\overline{\mathrm{X}}=35,63)$ ve 30-39 kıdem yılına sahip sınıf öğretmenlerinin puanları $(\bar{X}=35,25)$ arasında istatistiksel olarak anlamlı bir fark saptanmıştır $[F(3,113)=2,89, \mathrm{p} \leq 0,05]$. Yapılan Scheffe çoklu karşılaştırma testi sonucunda, anlamlı farkın, 10-19 kıdem yılına sahip sınıf öğretmenleri ile 20-29 kıdem yılına sahip sınıf öğretmenleri arasında 20-29 kıdem yılına sahip sınıf öğretmenleri lehine olduğu görülmüştür. Buna göre, 20-29 kıdem yılına sahip sınıf öğretmenlerinin teknolojik pedagojik alan bilgileri,10-19 kıdem yılına sahip sinıf öğretmenlerinin teknolojik pedagojik alan bilgilerinden anlamlı derecede daha yüksektir. Analiz sonucunda hesaplanan etki büyüklüğü $\left(\eta^{2}=0,07\right)$ bu farkın Cohen (1988) parametrelerine göre orta düzeyde etki büyüklüğüne sahip olduğunu göstermektedir.

Çalışmanın dördüncü alt probleminde, sınıf öğretmenlerinin teknolojik pedagojik alan bilgisi değerlendirme ölçeği alt boyutlarının öğretim yaptıkları sınıf türüne göre farklılaşıp farklılaşmadığı tek yönlü varyans analizi (one-way ANOVA) ile kontrol edilmiştir. Analiz sonuçları Tablo 8' de verilmiştir. 
Tablo 8. Sınıf Öğretmenlerinin Teknolojik Pedagojik Alan Bilgisi Değerlendirme Ölçeği Alt Boyutlarının Sahip Oldukları Sınıf Türüne İlişkin Durumları

\begin{tabular}{|c|c|c|c|c|c|c|}
\hline $\begin{array}{c}\text { Alt } \\
\text { Boyutlar }\end{array}$ & Gruplar & $\mathrm{N}$ & $\bar{X}$ & SS & $\mathrm{t}$ & $\mathrm{p}$ \\
\hline \multirow[t]{2}{*}{ TB } & Tek Şube & 107 & 27,07 & 4,89 & $-1,80$ & 0,08 \\
\hline & Birleştirilmiş 2 Şube & 10 & 29,90 & 3,14 & & \\
\hline \multirow[t]{2}{*}{$\mathrm{ABM}$} & Tek Şube & 107 & 13,17 & 1,68 & $-0,24$ & 0,82 \\
\hline & Birleştirilmiş 2 Şube & 10 & 13,30 & 1,89 & & \\
\hline \multirow[t]{2}{*}{ ABS } & Tek Şube & 107 & 12,64 & 1,94 & $-0,10$ & 0,92 \\
\hline & Birleştirilmiş 2 Şube & 10 & 12,70 & 2,11 & & \\
\hline \multirow[t]{2}{*}{$\mathrm{ABF}$} & Tek Şube & 107 & 12,75 & 1,87 & $-0,08$ & 0,94 \\
\hline & Birleştirilmiş 2 Şube & 10 & 14,00 & 1,52 & & \\
\hline \multirow[t]{2}{*}{$\mathrm{ABO}$} & Tek Şube & 107 & 14,00 & 1,52 & 1,72 & 0,09 \\
\hline & Birleştirilmiş 2 Şube & 10 & 13,10 & 2,18 & & \\
\hline \multirow[t]{2}{*}{ PB } & Tek Şube & 107 & 32,08 & 3,42 & 0,88 & 0,38 \\
\hline & Birleştirilmiş 2 Şube & 10 & 31,10 & 3,21 & & \\
\hline \multirow[t]{2}{*}{$\mathrm{PAB}$} & Tek Şube & 107 & 17,30 & 2,15 & 0,29 & 0,78 \\
\hline & Birleştirilmiş 2 Şube & 10 & 17,10 & 1,45 & & \\
\hline \multirow[t]{2}{*}{ TAB } & Tek Şube & 107 & 17,51 & 2,16 & 0,02 & 0,98 \\
\hline & Birleştirilmiş 2 Şube & 10 & 17,50 & 1,51 & & \\
\hline \multirow[t]{2}{*}{ ТPB } & Tek Şube & 107 & 16,75 & 2,62 & $-1,72$ & 0,09 \\
\hline & Birleştirilmiş 2 Şube & 10 & 18,20 & 1,62 & & \\
\hline \multirow[t]{2}{*}{ ТРAB } & Tek Şube & 107 & 34,46 & 4,56 & 0,58 & 0,56 \\
\hline & Birleştirilmiş 2 Şube & 10 & 33,60 & 2,76 & & \\
\hline
\end{tabular}

Tablo 8 incelendiğinde, tek şubeye sahip sinıf öğretmenlerinin teknolojik pedagojik alan bilgisi değerlendirme ölçeği alt boyut puanları ile birleştirilmiş sınıfa sahip sınıf öğretmenlerinin teknolojik pedagojik alan bilgisi değerlendirme ölçeği alt boyut puanları arasında anlamlı bir fark bulunmamıştır $(\mathrm{p}>0,05)$.

Çalışmanın dördüncü alt probleminde, sınıf öğretmenlerinin teknolojik pedagojik alan bilgisi değerlendirme ölçeği alt boyutlarının öğretim yaptıkları sınıf mevcutlarına göre farklılaşıp farklılaşmadığı tek yönlü varyans analizi (ANOVA) ile kontrol edilmiştir. Analiz sonuçları aşağıda Tablo 9'da verilmiştir. 
Tablo 9. Sınıf Öğretmenlerinin Teknolojik Pedagojik Alan Bilgisi Değerlendirme Ölçeği Alt Boyutlarının Sınıf Mevcutlarına İlişkin Durumları

\begin{tabular}{lllllll}
\hline $\begin{array}{l}\text { Alt } \\
\text { Boyutlar }\end{array}$ & $\begin{array}{l}\text { Varyansin } \\
\text { Kaynağı }\end{array}$ & $\begin{array}{l}\text { Kareler } \\
\text { Toplam } 1\end{array}$ & Sd & $\begin{array}{l}\text { Kareler } \\
\text { Toplamı }\end{array}$ & F & p \\
\hline TB & Gruplar arası & 46,80 & 3 & 15,60 & 0,65 & 0,58 \\
& Grup içi & 2605,04 & 109 & 23,90 & & \\
\hline ABM & Gruplar arası & 1,32 & 3 & 0,44 & 0,15 & 0,93 \\
& Grup içi & 320,49 & 109 & 2,94 & & \\
\hline ABS & Gruplar arası & 7,04 & 3 & 2,35 & 0,60 & 0,62 \\
& Grup içi & 427,35 & 109 & 3,92 & & \\
\hline ABF & Gruplar arası & 8,74 & 3 & 2,91 & 0,83 & 0,48 \\
& Grup içi & 284,20 & 109 & 3,53 & & \\
\hline ABO & Gruplar arası & 2,91 & 3 & 0,97 & 0,37 & 0,78 \\
& Grup içi & 286,59 & 109 & 2,63 & & \\
\hline PB & Gruplar arası & 12,90 & 3 & 4,30 & 0,36 & 0,78 \\
& Grup içi & 1289,82 & 109 & 11,83 & & \\
\hline PAB & Gruplar arası & 2,18 & 3 & 0,73 & 0,16 & 0,92 \\
& Grup içi & 487,38 & 109 & 11,83 & & \\
\hline TAB & Gruplar arası & 2,75 & 3 & 0,92 & 0,20 & 0,90 \\
& Grup içi & 499,44 & 109 & 4,58 & & \\
\hline TPB & Gruplar arası & 0,40 & 3 & 0,13 & 0,02 & 1,00 \\
& Grup içi & 744,05 & 109 & 6,83 & & \\
\hline TPAB & Gruplar arası & 10,41 & 3 & 3,47 & 0,17 & 0,92 \\
& Grup içi & 2227,71 & 109 & 20,44 & & \\
\hline
\end{tabular}

Tablo 9’da görüldüğü gibi, 0-9 sinıf mevcuduna sahip sinıf öğretmenleri, 10-19 sinıf mevcuduna sahip sınıf öğretmenleri, 20-29 sınıf mevcuduna sahip sınıf öğretmenleri ile 3039 sınıf mevcuduna sahip sınıf öğretmenlerinin teknolojik pedagojik alan bilgisi değerlendirme ölçeği alt boyut puanları arasında anlamlı bir farklılık olmadığı görülmüştür $(\mathrm{p}>0,05)$.

\section{Tartışma ve Sonuçlar}

Bu araştırmada, ilkokullarda görev yapan sınıf öğretmenlerinin teknolojik pedagojik alan bilgileri bazı değişkenlere göre incelenmiştir. Araştırma sonuçlarına göre öğretmenlerin teknolojik pedagojik alan bilgisi ölçeğinin tüm alt boyutlarının, öğretmenlerin öğretim yaptıkları sınıfın mevcudu ve sınıf türü ile mezun oldukları bölümlere göre farklılaşmadığı görülmüştür. Araştırmanın diğer bulguları değerlendirildiğinde sınıf öğretmenlerin teknolojik bilgi puanlarının cinsiyete göre istatistiksel olarak farklılaştığı görülmüştür. Bu sonucu Erdoğan ve Şahin'in (2010) ve Koh, Chai ve Tsai'nin (2010) çalışmaları desteklemektedir. Teknolojik pedagojik alan bilgisinin teknoloji bilgisi alt boyutunda erkek öğretmenlerin kendilerini daha yeterli gördükleri tespit edilmiştir. Bunun sebebinin 
erkeklerin teknolojiye karşı olan ilgilerinin daha yüksek olmasından kaynaklandığı söylenebilir.

Sınıf öğretmenlerinin kıdem yıllarına göre teknolojik pedagojik alan bilgisi alt boyutlarından pedagojik alan bilgisi, teknolojik pedagojik bilgi ve teknolojik pedagojik alan bilgisi boyutlarında anlamlı farklılık tespit edilmiştir. Pedagojik alan bilgisi alt boyutunda 30-39 kıdem yılına sahip sınıf öğretmenlerinin kendilerini 10-19 kıdem yılına sahip sınıf öğretmenlerinden daha yeterli gördüğü sonucuna ulaşılmıştır. Bu durum Karadeniz ve Vatanartıran'ın (2015) çalışmasıyla paralellik göstermektedir. Öğretmenlerin, öğretim stratejileri, yöntem ve teknikleri, ölçme değerlendirme bilgilerini konu alanına göre seçmekte ve etkili kullanmakta daha yetkin olma durumunun sahip oldukları tecrübeden kaynaklandığı düşünülebilir. Teknolojik pedagojik bilgi boyutunda 20-29 kıdem yılına sahip sınıf öğretmenlerinin kendilerini 10-19 kıdem yılına sahip sınıf öğretmenlerinden daha yeterli gördüğü sonucuna ulaşılmıştır. Bu sonuca göre pedagojik bilgileri, teknoloji ile harmanlamadaki yetkinliğinin sebebinin, tecrübe ile birlikte gelen pedagojik bilgi hakimiyetinin sağladığı güven sonucu, teknolojiyi daha yüksek bir farkındalıkla entegre edebilme olduğu düşünülmektedir. Teknolojik pedagojik alan bilgisi alt boyutunda yine 2029 kıdem yılına sahip sınıf öğretmenlerinin 10-19 kıdem yılına sahip sınıf öğretmenlerine kıyasla kendilerini daha yeterli gördügü tespit edilmiştir. Bunun sebebinin, kıdem yılı düşük öğretmenlerin teknoloji bilgisinin daha yüksek çıtığ çalışmalara ve beklentilere rağmen, kıdem yılı yüksek öğretmenlerde pedagoji bilgisi ve pedagojik alan bilgisinin daha yüksek olmasının, teknolojiyi entegre etmelerinde daha az zorlanmaları düşüncesini kuvvetlendirmektedir.

İleride yapılacak çalışmalarda teknolojik pedagojik bilgi ve teknolojik pedagojik alan bilgisinde kıdem yılı 20-29 olan sınıf öğretmenlerinin 10-19 kıdem yılına sahip sınıf öğretmenlerinden neden yüksek çıktığına dair derinlemesine bir araştırma yapmak için görüşmeler yapılabilir.

\section{Kaynaklar}

Aşkar, P. \& Umay, A. (2001). İlköğretim matematik öğretmenliği öğrencilerinin bilgisayarla ilgili öz-yeterlik alg1sı. Hacettepe Üniversitesi Eğitim Fakültesi Dergisi, 21, 1-8.

Baran, E. \& Canbazoğlu Bilici, S. (2015). Fen bilimleri öğretmenlerinin teknolojik pedagojik alan bilgisine yönelik öz-yeterlik düzeylerinin incelenmesi: boylamsal bir araştırma. Gazi Üniversitesi Gazi Ĕ̆itim Fakültesi Dergisi, 35(2), 285-36.

Büyüköztürk, Ş. (2012). Sosyal bilimler için veri analizi el kitabı. Ankara: Pegem Akademi. 
Büyüköztürk, Ş., Kılıç Çakmak, E., Akgün, Ö. E., Karadeniz, Ş. \& Demirel, F. (2014). Bilimsel araştırma yöntemleri (18.Baskı). Ankara: Pegem Yayıncılık.

Cohen, J. (1988). Statistical power analysis for the behavioral sciences (2 ${ }^{\text {nd }}$ Ed.). Hillsdale, NJ: Lawrence Erlbaum Associates.

Erdoğan, Ş. \& İsmail, Ş. (2010). Relationship between math teacher candidates' technological pedagogical and content knowledge (tpack) and achievement levels. Procedia Social and Behavioral Sciences, 2, 2707-2711.

Gömleksiz, M.N. \& Fidan, E. K. (2011). Self-Efficacy perception levels of prospetive teachers enrolled at pedagogical formation course toward web pedagogical content knowledge. International Periodical for the Languages, Literature and History of Turkish or Turkic, 6(4), 593-620.

Hacıömeroğlu, G., Şahin, Ç. \& Arcagök, S. (2014). Öğretmen adaylarının teknolojik pedagojik alan bilgisini değerlendirme ölçeğinin türkçe'ye uyarlama çalışması. Eğitimde Kuram ve Uygulama Dergisi, 10(2), 297-315.

Hırça, N. \& Şimşek, H. (2012). Öğretmen adaylarının fen konularına yönelik tekno-pedagojik bilgi bütünleştirmelerinin geliştirilmesi ve değerlendirilmesi. Necatibey Ĕ̆itim Fakültesi Elektronik Fen ve Matematik Ĕ̈itimi Dergisi, 7(1), 57-82.

Jang, S. J. \& Chan, K. C. (2010). From pck to tpack: Developing a transformative model for pre-service science teachers. Journal Science Educational Tecnology, 19, 553-564.

Karadeniz, Ş. \& Vatanartıran, S. (2015). Sınıf öğretmenlerinin teknolojik pedagojik alan bilgilerinin incelenmesi. İlköğretim Online, 14(3), 1018-1028.

Karakuyu, Y. \& Karakuyu, A. (2016). Motivasyon ve öz-yeterliğin sınıf öğretmeni adaylarının teknolojik pedagojik alan bilgilerine (tpab) katkısı. Uşak Üniversitesi Ĕ̆itim Araştırmaları Dergisi 2(1), 89- 100.

Koehler, M. J. \& Mishra, P. (2005). What happens when teachers design educational technology? The development of technological pedagogical content knowledge. Journal of Educational Computing Research, 32(2) 131-152

Koehler, M.J., \& Mishra, P. (2009). What is technological pedagogical content knowledge? Contemporary Issues in Technology and Teacher Education, 9(1), 60-70.

Koh, J.H.L., Chai, C. S. \& Tsai, C. C. (2010). Examining the technological pedagogical content knowledge of singapore preservice teachers with a large-scale survey. Journal of Computer Assisted Learning, 26, 563-573.

Koh, J.H.L. \& Sing, C.C. (2011, Aral1k). Modeling pre-service teachers' technological pedagogical content knowledge (tpack) perceptions: The influence of demographic factors and tpack constructs. Paper presented at ascilite Australian Society for Computers in Learning in Tertiary Education Annual Conference, Hobart, Australia.

Mishra, P. \& Koehler, M. (2006). Technological pedagogical content knowledge: A framework for teacher knowledge. The Teachers College Record, 108(6), 1017-1054.

Sancar Tokmak, H., Yavuz Konokman, G., \& Yanpar-Yelken, T. (2013). Mersin üniversitesi okul öncesi öğretmen adaylarının teknolojik pedagojik alan bilgisi (tpab) özgüven algılarının incelenmesi. Ahi Evran Üniversitesi Kırşehir Ĕ̆itim Fakültesi Dergisi, 14(1), 3551. 
Schmidt, D. A., Baran, E., Thompson, A. D., Mishra, P., Koehler, M. J. \& Shin, T. S. (2009). Technological pedagogical content knowledge (tpack): The development and validation of an assessment instrument for preservice teachers. Journal of Research on Technology in Education, 42(2), 27.

Yanpar Yelken, T., Sancar Tokmak, H., Özgelen, S. \& Incikabı, L. (2013). Teknolojikpedagojik-alanbilgisi (tpab) çerçevesi ve bu çerçevenin milli eğitim bakanlığı fen ve matematik eğitimi programındaki yeri. Yanpar-Yelken, T., Sancar Tokmak, H., Özgelen, S. \& İncikabı, L. (Ed.) Fen ve matematik eğitiminde teknolojik pedagojik alan bilgisi temelli öğretim tasarımları (s.1-12). Ankara: Anı Yayıncılık. 